TECHNICAL NOTE
S. Thiriat
S. Riehm
S. Kremer
E. Martin
F. Veillon

\section{Apparent Diffusion Coefficient Values of Middle Ear Cholesteatoma Differ from Abscess and Cholesteatoma Admixed Infection}

\begin{abstract}
SUMMARY: A retrospective study was conducted on a cohort of 15 patients who underwent surgery because cholesteatoma or abscess was suspected. All patients had MR imaging prior to surgery with diffusion-weighted images (DWI) from which the apparent diffusion coefficient (ADC) value was calculated. Using this technique, we were able to determine 3 distinct ADC value ranges corresponding to the 3 groups of lesions found at surgery (pure cholesteatoma, cholesteatoma with infection, and abscess or infection). This needs to be confirmed by further studies with a wider range of patients.
\end{abstract}

C holesteatoma is a locally aggressive middle ear lesion consisting of squamous cells with desquamatous debris that requires surgical treatment. Some may be superinfected. These processes may be difficult to distinguish from pure abscess on conventional imaging.

Currently, the most effective method for imaging cholesteatoma is CT, with MR imaging reserved for difficult cases such as the detection of recurrence. The MR examination should include T1-weighted, T1 postgadolinium contrast, T2weighted, and diffusion-weighted/apparent diffusion coefficient (ADC) sequences. Cholesteatoma typically shows intermediate T1 signal intensity without significant enhancement after 30 to 45 minutes and hyperintense signal intensity on T2-weighted and diffusion-weighted (DW) images. ${ }^{1-5}$

Cholesteatoma shows increased DW signal intensity for the same reason as a brain epidermoid cyst, another lesion containing epidermoid cells, as previously reported in the literature. $^{5}$ Although restricted diffusion does contribute to increased DW signal intensity, the increased signal intensity predominantly results from the effects of T2 shinethrough. ${ }^{6-9}$ Annet et $\mathrm{al}^{7}$ found that the mean $\mathrm{ADC}$ value was approximately $1.070 \times 10^{-3} \mathrm{~mm}^{2} / \mathrm{s}$ (range, $1.280-0.807 \times 10^{-3}$ $\left.\mathrm{mm}^{2} / \mathrm{s}\right) .^{7}$

A brain abscess also shows increased DW signal intensity; however, this is primarily caused by restricted diffusion from the increased viscosity of the fluid inside. ${ }^{10-11}$ Chang et $\mathrm{al}^{11}$ demonstrated that the mean ADC value in an abscess was $0.650 \times 10^{-6} \mathrm{~mm}^{2} / \mathrm{s}$.

From these differences, it can be inferred that the ADC value could be used to help differentiate epidermoid lesions from abscess. The aim of our study was to evaluate whether ADC values could be measured to show a pattern that could differentiate cholesteatoma from abscess and cholesteatoma with infection.

Received September 10, 2008; accepted after revision November 21.

From the Department of Radiology (S.T.), Hautepierre Strasbourg, Strasbourg, France; and Departments of Radiology (S.R., S.K., F.V.) and Otolaryngology (E.M.), Hautepierre Strasbourg, Hôpital de Hautepierre, Cedex, France.

Please address correspondence to Sébastien Thiriat, CHU, Radiology, Moliere St, Strasbourg, 67098, France; e-mail: sebastienthiriat@voila.fr

DOI 10.3174/ajnr.A1473

\section{Materials and Methods}

\section{Patients}

We conducted a retrospective cohort study on 15 patients $(7$ male and 8 female; age range, 6-72 years; mean, 36.7 years), who underwent MR imaging showing findings of either cholesteatoma or abscess before surgery from January 2007 to August 2008.

We divided this cohort into 3 different groups corresponding to the surgical findings: the first group had pure cholesteatoma, the second had a mixed-pattern lesion of cholesteatoma associated with infection, and a third group showed abscess and infection.

For each surgical group, we retrospectively measured the ADC value as found on the MR imaging study performed before surgery (Table 1).

\section{Imaging Technique}

We performed the MR imaging study on a $1.5 \mathrm{~T}$ MR unit (1.5T Avanto; Siemens, Erlangen, Germany). All patients were evaluated with the following protocol:

T1 axial spin-echo fat saturated (17 slides; matrix, $384 \times 384$; voxel size, $0.6 \times 0.6 \times 1.5 \mathrm{~mm}$; TR, $719 \mathrm{~ms}$; TE, $13 \mathrm{~ms} ; 2$ averages).

T2 axial spin-echo ( 25 slides; matrix, $256 \times 256$; voxel size, $0.9 \times 0.9 \times 4 \mathrm{~mm}$; TR, $4490 \mathrm{~ms}$; TE, $100 \mathrm{~ms} ; 1$ average).

High-resolution T2 axial (gradient-echo, 64 slides; matrix, $320 \times 384$; voxel size, $0.5 \times 0.5 \times 0.4 \mathrm{~mm}$; TR, $11.6 \mathrm{~ms}$; TE, $5.8 \mathrm{~ms})$.

DW acquisition axial and coronal (20 slides; TR, $4000 \mathrm{~ms}$; TE, 107 ms; matrix, $128 \times 128$; voxel size, $1.5 \times 1.5 \times 3 \mathrm{~mm} ; b=0$ and $b=$ $1000 \mathrm{~s} / \mathrm{mm}^{2} ; 5$ averages). ADC cartography was systematically done with use of these acquisition parameters.

Half-Fourier acquired single-shot turbo spin-echo diffusionweighted acquisition axial and coronal (15 slides; TR, $2000 \mathrm{~ms}$; TE, $132 \mathrm{~ms}$; matrix, $128 \times 64$; voxel size, $2.5 \times 1.2 \times 3 \mathrm{~mm} ; b=1000$ $\mathrm{s} / \mathrm{mm}^{2} ; 5$ averages).

\begin{tabular}{lccr}
\hline \multicolumn{4}{l}{ Table 1: ADC values for the 3 different surgical groups } \\
\hline Patient & \multicolumn{3}{c}{ ADC Value $\left(\times 10^{-3} \mathrm{~mm}^{2} / \mathrm{s}\right)$} \\
\cline { 2 - 4 } No. & Group 1 & Group 2 & Group 3 \\
\hline 1 & 0.847 & 0.628 & 0.571 \\
2 & 1.054 & 0.774 & 0.568 \\
3 & 1.046 & 0.630 & 0.107 \\
4 & 0.917 & & \\
5 & 1.047 & & \\
6 & 0.790 & & \\
7 & 0.871 & & \\
8 & 0.698 & & \\
9 & 0.863 & & \\
\hline
\end{tabular}



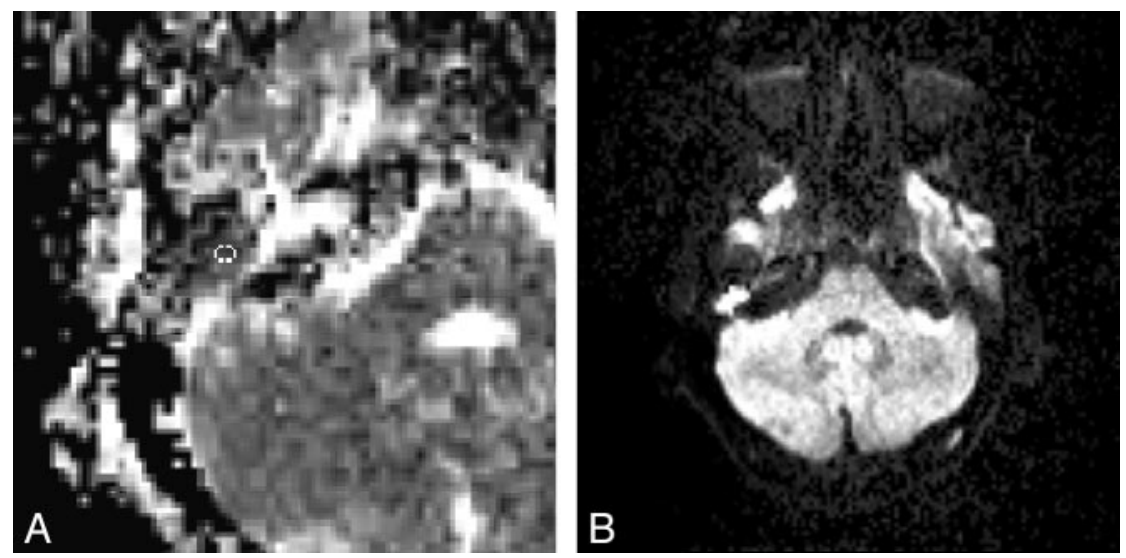

Fig 1. $A, A D C$ value cartography and region of interest to calculate $\mathrm{ADC}$ value. $B$, DW image.

T1 axial spin-echo fat saturated, 45 minutes after gadolinium chelate injection ( 17 slides; matrix, $384 \times 384$; voxel size, $0.6 \times 0.6 \times 1.5$ mm; TR, $719 \mathrm{~ms}$; TE, $13 \mathrm{~ms}$; 2 averages).

All examinations were reviewed by a radiologist who had 15 years' experience in middle ear imaging. For each patient, this radiologist calculated the ADC value in a selected region of interest on the cartography on the Avanto workstation (Siemens) (Fig 1). These regions of interest were placed in an area matching the suspected cholesteatoma or abscess of the middle ear according to the usual sequences and were approximately $11 \mathrm{~mm}^{2}$ in volume.

To test the reliability of the measurements, all were repeated twice (2 months apart) by the same radiologist experienced in otolaryngologic imaging. The second measurement was taken without checking the first results. The results are listed in Table 2. These results were subjected to the correlation test as detailed in Portney and Watkins. ${ }^{12}$

The size of each middle ear signal intensity abnormality was evaluated and an average for the cohort calculated. Finally, we retrospectively compared the diagnosis made by DWI only with the diagnosis inferred by using DWI and ADC values compared with the surgical results (Table 3 ).

\section{Results}

The surgical results of the 15 patients included in the study showed that 9 had pure cholesteatoma (group 1), 3 had cholesteatoma with superinfection (group 2), and 3 had abscess or

\begin{tabular}{|c|c|c|}
\hline $\begin{array}{l}\text { Patient No./ } \\
\text { Surgical Group }\end{array}$ & $\begin{array}{l}\begin{array}{c}\text { ADC Value } \\
\left(\times 10^{-3} \mathrm{~mm}^{2} / \mathrm{s}\right)\end{array} \\
\text { First Calculation }\end{array}$ & $\begin{array}{c}\text { ADC Value } \\
\left(\times 10^{-3} \mathrm{~mm}^{2} / \mathrm{s}\right) \\
\text { Second Calculation }\end{array}$ \\
\hline $1 / \mathrm{g} 1$ & 0.847 & 0.866 \\
\hline 2/g1 & 1.054 & 1.015 \\
\hline $3 / g 1$ & 1.046 & 1.026 \\
\hline 4/g1 & 0.917 & 0.805 \\
\hline $5 / 91$ & 1.047 & 1.054 \\
\hline 6/g1 & 0.790 & 0.857 \\
\hline $7 / g 1$ & 0.871 & 0.832 \\
\hline 8/g1 & 0.698 & 0.696 \\
\hline 9/g1 & 0.863 & 0.824 \\
\hline $1 / \mathrm{g} 2$ & 0.628 & 0.668 \\
\hline 2/g2 & 0.774 & 0.670 \\
\hline $3 / g 2$ & 0.630 & 0.621 \\
\hline $1 / g 3$ & 0.571 & 0.531 \\
\hline $2 / 93$ & 0.568 & 0.576 \\
\hline 3/g3 & 0.107 & 0.075 \\
\hline
\end{tabular}

Note:-g1 indicates group 1; g2, group 2; g3, group 3. pure infection with no evidence of cholesteatoma (group 3). The calculated ADC values of these 3 groups are listed in Table 1.

In summary, the group 1 patients had an ADC value up to $0.698 \times 10^{-3} \mathrm{~mm}^{2} / \mathrm{s}$, the group 2 patients showed a lower ADC value $\left(0.628\right.$ and $\left.0.774 \times 10^{-3} \mathrm{~mm}^{2} / \mathrm{s}\right)$, and the group 3 patients, containing abscess or pure infection without cholesteatoma, showed a ADC value under $0.571 \times 10^{-3} \mathrm{~mm}^{2} / \mathrm{s}$ (taking into account the first measurement).

The range of signal intensity abnormality on which we performed the measurements was from $16 \mathrm{~mm}^{2}$ to $266 \mathrm{~mm}^{2}$. The calculated average is approximately $84 \mathrm{~mm}^{2}$.

All of the values were calculated twice and are listed in Table 2. We calculated the interclass correlation coefficient (ICC) using the method detailed in Portney and Watkins. ${ }^{12}$ The calculated ICC is 0.98 , substantiating the reliability of the measurements. Table 3 shows 4 misdiagnoses with use of the DWI alone, whereas 1 diagnosis for the DWI combined with the ADC values (the latest were made retrospectively).

\section{Discussion}

To date, no study has attempted to use ADC values to differentiate cholesteatoma from abscess or mixed-pattern lesions. Considering the findings reported in the literature, we ex-

\begin{tabular}{|c|c|c|}
\hline $\begin{array}{l}\text { Patient No./ } \\
\text { Surgical Group }\end{array}$ & $\begin{array}{l}\text { Diagnosis Made } \\
\text { by DWI Alone }\end{array}$ & $\begin{array}{c}\text { Diagnosis Inferred by } \\
\text { DWI with Calculated } \\
\text { ADC Values }\end{array}$ \\
\hline $1 / g 1$ & $\mathrm{G} 1$ & $\mathrm{G} 1$ \\
\hline $2 / g 1$ & G1 & G1 \\
\hline $3 / g 1$ & G1 & G1 \\
\hline 4/g1 & G1 & G1 \\
\hline $5 / g 1$ & G1 & G1 \\
\hline 6/g1 & G1 & $\mathrm{G} 1$ or 2 \\
\hline 7/g1 & G1 & G1 \\
\hline 8/g1 & G1 & G2 \\
\hline 9/g1 & G1 & G1 \\
\hline 1/g2 & G1 & G2 \\
\hline 2/g2 & G1 & $\mathrm{G} 1$ or 2 \\
\hline 3/g2 & $\mathrm{G} 1$ or 2 & G2 \\
\hline 1/g3 & G2 & G3 \\
\hline 2/g3 & $\mathrm{G} 1$ or 2 & G3 \\
\hline 3/g3 & G3 & G3 \\
\hline
\end{tabular}

Note:-DWI indicates diffusion-weighted imaging; G1, diagnosed as a group 1 patient; G2 diagnosed as a group 2 patient; G3, diagnosed as a group 3 patient. 

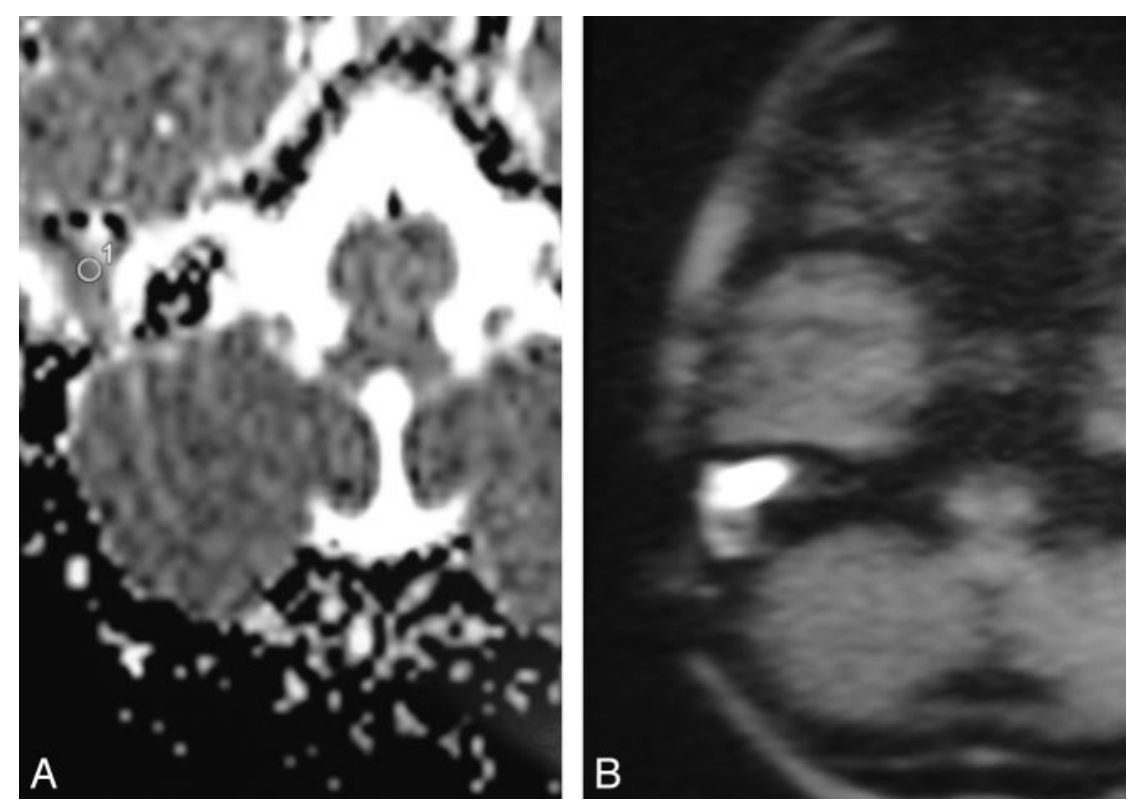

Fig 2. $A$, corresponding calculated $A D C$ value on $A D C$ cartography $\left(0.917 \times 10^{-3} \mathrm{~mm}^{2} / \mathrm{s}\right)$. $B$, DW image of a group 1 patient.
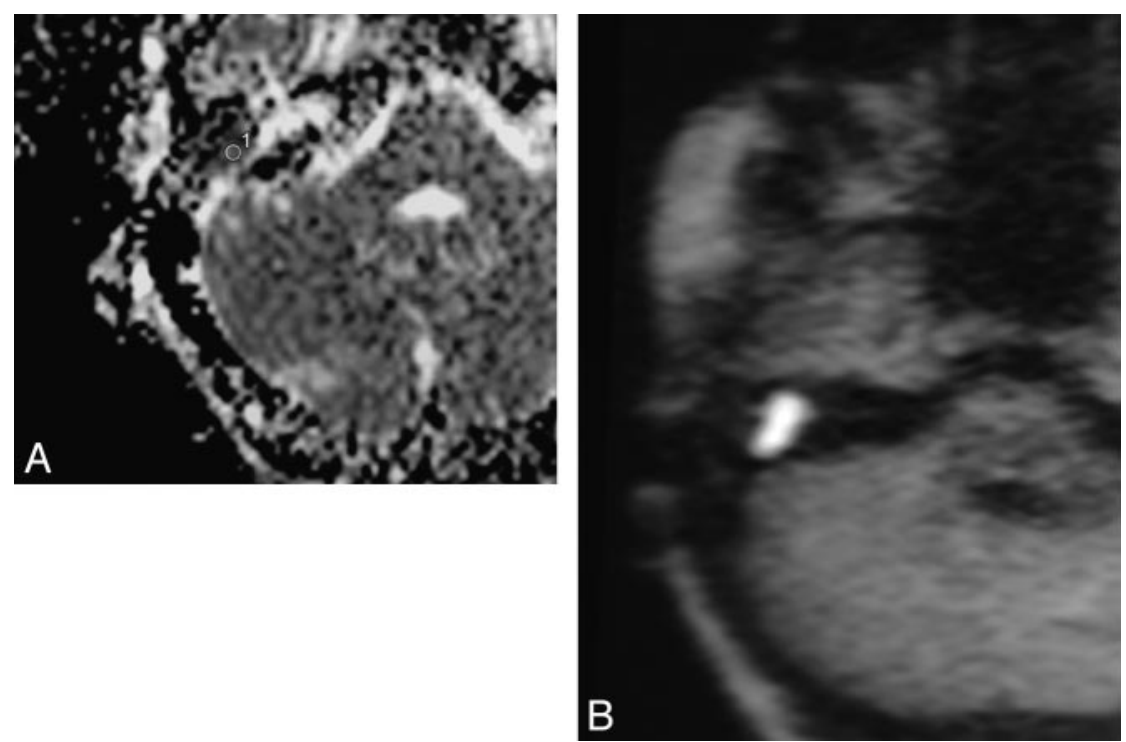

Fig 3. $A$, corresponding calculated $A D C$ value on $A D C$ cartography $\left(0.774 \times 10^{-3} \mathrm{~mm}^{2} / \mathrm{s}\right)$. $B$, DW image of a group 2 patient.

pected a high ADC value for the pure cholesteatoma with a mean ADC value of approximately $1 \times 10^{-3} \mathrm{~mm}^{2} / \mathrm{s}$. The cohort of 9 patients with surgically proved pure cholesteatoma had a mean ADC value of $0.903 \times 10^{-3} \mathrm{~mm}^{2} / \mathrm{s}$ (calculated with the ADC values from Table 1). This result is consistent with what was expected.

Previous articles evaluating brain abscess ADC values showed relatively low values, including the article by Chang et $\mathrm{al}^{11}$ that found an average of approximately $0.650 \times 10^{-3}$ $\mathrm{mm}^{2} / \mathrm{s}$ (calculated with the ADC values from Table 1). In our cohort of 3 patients, we obtained a mean ADC value of $0.415 \times 10^{-3} \mathrm{~mm}^{2} / \mathrm{s}$, which is somewhat lower than what was expected.

As expected, the mixed-pattern lesions showed intermediate $\mathrm{ADC}$ values, likely the result of the combination of both tissue ADC ranges. Our results showed a mean ADC value of $0.677 \times 10^{-3} \mathrm{~mm}^{2} / \mathrm{s}$ (calculated with the ADC values from Table 1), that is, between 0.415 and $0.903 \times 10^{-3} \mathrm{~mm} / \mathrm{s}$.

The concordance between the surgical findings and the calculated ADC value suggests that ADC values could be used to allow greater specificity to differentiate cholesteatoma from middle ear abscess or mixed-pattern lesions. Indeed, the comparison between the 2 methods (DWI alone vs DWI and calculated ADC values) shows that calculating the ADC value can improve the precision of the diagnosis ( 1 mistake with use of this method vs 4 mistakes otherwise).

In our study, the mean size of the middle ear abnormalities in DW images was $84 \mathrm{~mm}^{2}$ (range, $16-266 \mathrm{~mm}^{2}$ ). Compared with the study reported by De Foer et al, ${ }^{13}$ the lesion values are substantially higher, resulting mainly from the measurement technique. Indeed, as shown in Fig 1, the region of interest is placed on the center of the lesion. With a very small lesion, it is much more difficult, even impossible, to draw the region of interest without taking in the surrounding tissue, which would lead to false results. This is a limitation in the technique reported herein. To illustrate this, we show an example of a measurement for each group (Figs 2-4).

Given the small sample size in this study, a larger study with a wider range of patients is recommended to confirm the results before drawing a definitive conclusion on the importance 

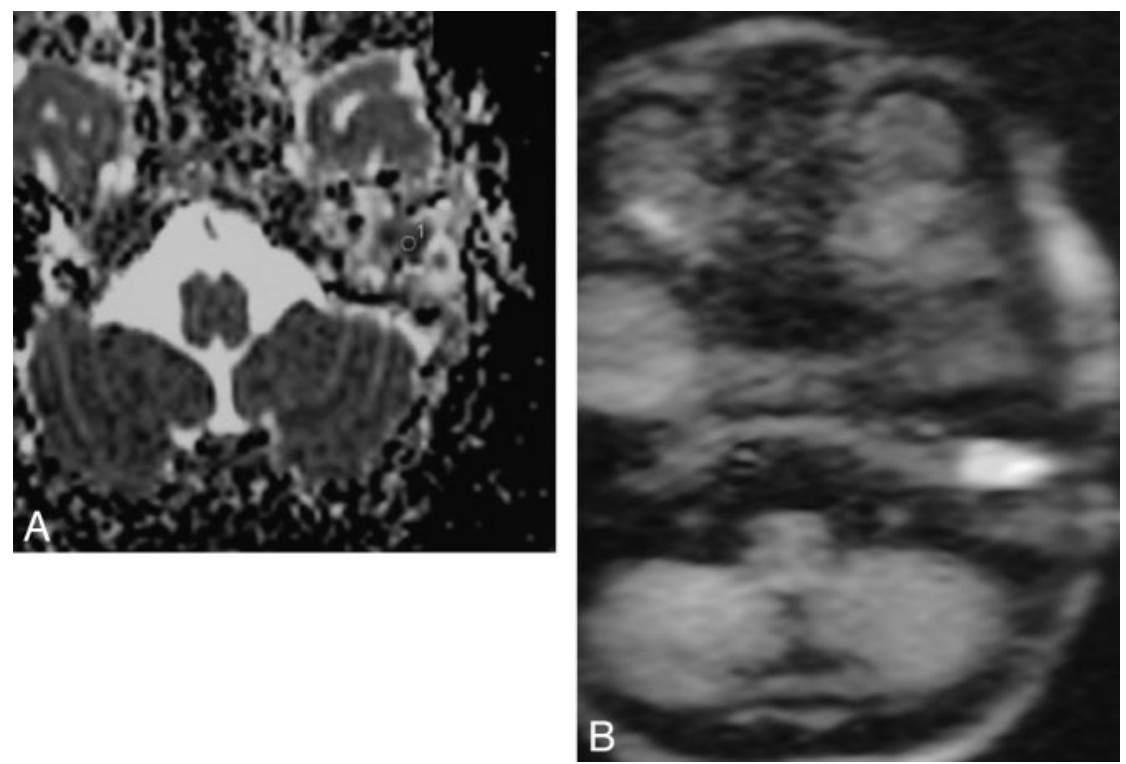

Fig 4. $A$, corresponding calculated $A D C$ value on $A D C$ cartography $\left(0.570 \times 10^{-3} \mathrm{~mm}^{2} / \mathrm{s}\right) . B$, DW image of a group 3 patient.

of ADC values to differentiate middle ear pathologic conditions.

\section{Conclusions}

In MR imaging of the middle ear, there is typically no reliable way to differentiate between abscess and cholesteatoma. Calculating the $\mathrm{ADC}$ value of a region of interest placed on the lesion, we were able to determine 3 distinct ADC value ranges corresponding to the 3 groups of lesions found at surgery (pure cholesteatoma, cholesteatoma with infection, and abscess or infection). One limitation seemed to be the size of the lesion because it is likely that the measurement cannot be adequately taken on very small lesions. These results need to be confirmed by additional studies with a larger sample size and a wider range of patients.

\section{References}

1. Kimitsuki T, Suda Y, Kawano H, et al. Correlation between MRI findings and second-look operation in cholesteatoma surgery. ORL J Otorhinolaryngol Relat Spec 2001;63:291-93

2. Heran F, Williams M. MRI of the ear. J Neuroradiol 2003;30:131-45

3. Kosling S, Bootz F. CT and MR imaging after middle ear surgery. Eur J Radiol 2001;40:113-18
4. Vanden Abeele D, Coen E, Parizel PM, et al. Can MRI replace a second look operation in cholesteatoma surgery? Acta Otolaryngol 1999;119:555-61

5. Dubrulle F, Souillard R, Chechin D, et al. Diffusion-weighted MR imaging sequence in the detection of postoperative recurrent cholesteatoma. Radiology 2006;238:604-10

6. Schaefer PW, Grant PE, Gonzalez RG. Diffusion-weighted MR imaging of the brain. Radiology 2000;217:331-45

7. Annet L, Duprez T, Grandin C, et al. Apparent diffusion coefficient measurements within intracranial epidermoid cysts in six patients. Neuroradiology 2002;44:326-28

8. Hakyemez B, Aksoy U, Yildiz H, et al. Intracranial epidermoid cysts: diffusion-weighted, FLAIR and conventional MR findings. Eur J Radiol 2005;54:214-20

9. Chen S, Ikawa F, Kurisu K, et al. Quantitative MR evaluation of intracranial epidermoid tumors by fast fluid-attenuated inversion recovery imaging and echo-planar diffusion-weighted imaging. AJNR Am J Neuroradiol 2001;22: 1089-96

10. Leuthardt EC, Wippold FJ, Oswood MC, et al. Diffusion weighted MR imaging in the preoperative assessment of brain abscesses. Surg Neurol 2002;58:395-402

11. Chang SC, Lai PH, Chen WL, et al. Diffusion-weighted MRI features of brain abscess and cystic or necrotic brain tumors: comparison with conventional MRI. Clin Imaging 2002;26:227-36

12. Portney LG, Watkins MP. Foundation of Clinical Research. Applications and Practice. Norwalk, Conn: Appleton and Lange; 1993:509-16

13. De Foer B, Vercruysse JP, Bernaerts A, et al. The value of single-shot turbo spin-echo diffusion-weighted MR imaging in the detection of middle ear cholesteatoma. Neuroradiology 2007;49:841-48 